Research Article

\title{
Automatic Synthesis of Optimal Fixed Structure QFT Controller for Pneumatic Servo Actuator System using Multi-objective Particle Swarm Optimization
}

\author{
Nitish Katal* and Shiv Narayan \\ Electrical Engineering Department, PEC University of Technology, Chandigarh, India.
}

Received 7 May 2016; Accepted 18 September 2016

\begin{abstract}
Loop shaping is the prime step for synthesising Quantitative Feedback Theory (QFT) based robust controllers. The synthesised QFT controller assures performance robustness in presence of parametric plant uncertainties'. In this paper for automating the controller synthesis, loop-shaping problem has been posed as multi-objective optimization problem, which is solved using particle swarm optimization algorithm. The presented approach, explores a template and bounds free method for the automatic synthesis of fixed structure QFT controller for a highly uncertain pneumatic servo actuator system. The paper also explores the use of level diagrams for choosing the ideal solution from the Pareto optimal set. From the results obtained, the designed controller offers performance robustness over a range of plant's parametric uncertainty.
\end{abstract}

Keywords:Signature Quantitative feedback theory; Multi-objective Particle Swarm Optimization; Automatic Loop Shaping; Robust Stability; Level Diagrams.

\section{Introduction}

Real engineering systems are prone to external interferences and disturbances, and thus their reliability must be assured. As the quality of control directly affects the quality of products and processes' safety, emphasis must be given on the design of efficient robust optimal control systems [1]. The modeling of disturbances into the plant model while designing the control systems must be accomplished, as there are always distinctions between the mathematical model used in design process and the real system [2].

Bode [3] led the foundation of incorporating uncertainties' in control system design for feedback amplifier design, followed by Issac Horowitz. Horowitz along with Sidi [4] introduced a frequency domain controller design technique of Quantitative Feedback Theory (QFT) in 1960 's. QFT emphasizes only on the use of feedback for minimizing the effect of uncertainties' on the system, by shaping the feedback such that pre-defined robustness and objectives (QFT Bounds) are satisfied [4]. Loop shaping of the open loop transmission $L_{0}(s)$ is the prime step synthesising the QFT controller. Loop shaping is performed on Nichols charts such that, $L_{0}(j \omega)$ satisfied all the bounds at each design frequency. Loop shaping on Nichols charts requires a lot of design experience and sometimes can be challenging even for expert control designer and still there is no guarantee that an optimal controller has been found [5]. Automation of the loop-shaping step in QFT is still an open problem.

QFT has been implemented successfully in several diverse fields $[6-13]$, but most of the work focuses on the manual loop shaping. It becomes challenging to design

*E-mail address: nitishkatal@gmail.com

ISSN: $1791-2377$ @ 2016 Eastern Macedonia and Thrace Institute of Technology. All rights reserved. stable controllers for uncertain and non-minimum phase systems with complicated characteristics and even the most scrupulous design doesn't assure achieving the perfect optimal controller. Initial efforts have been carried out by Gera and Horowitz [14] followed by Balance et. al [15], but very high order were obtained. Fixed structure QFT controllers have been automatically designed [16 - 18] but these methods are based on rational approximation of the controller and a low order controller gives a poor response. Another approach, which automates the synthesis of QFT controller, is based on searching of controller from a dense set of controllers [19]. PSV Nataraj et. al [20] translated the QFT design requirements in terms of quadratic inequalities and used interval constraint satisfaction technique for automating the QFT design procedure [21 - 25]. The controllers designed with ICST based approach suffer form overdosing over the frequency range [26].

Conventional gradient-based optimization algorithms cannot solve the automatic loop shaping, as it is a non-linear, non-convex multi-objective problem. Nature inspired algorithms are being widely used in control system design in which the conventional control theory fails. In QFT controller design initial attempts have been made by GraciaSanz et al. [27] to automated the loop shaping process using genetic algorithms. Many nature inspired algorithms have been successfully used for automating the QFT loop shaping step [28 - 34], but some of these techniques still require the generation of template and bounds on Nichols charts and most of the work focuses on the minimization of the objective function expressed as weighted sum of all the objectives, which requires a careful weight tuning.

This paper implements the designed optimal QFT controller for a highly uncertain pneumatic servo actuator system. In compliance with safety requirements, the air pressure supply is kept low in pneumatic actuators. This makes it difficult to ensure high performance position 
control, as low pressure makes it impractical to attain the possible actuator stiffness. Thus the system to get along varying loads and this affects the design of high bandwidth systems. The uncertain dynamics, non-linear valves and varying loads in pneumatic servo actuator system directly affect the process's safety and the quality of goods. It makes it crucial for the control system to exert a quality control. Thus controller must be designed such that it offers a robust response over a range of plant's parametric uncertainties.

In this paper, the QFT controller synthesis has been posed as multi-objective optimization problem and multiobjective PSO has been used to solve it. The Pareto optimal set (POS) of solutions aids the designer in choosing the desired trade-off among conflicting objectives. The paper uses the method [35], which offers a templates and bounds free approach for automating the QFT controller synthesis. At the end of the optimization process, the paper also explores the use of level diagrams for choosing the ideal solution form the POS by aiding the decision maker by intuitively visualizing the $m$-dimensional Pareto in simple and accurate manner to choose ideal trade-off among QFT design objectives. The procedure eases the controller designer to design optimal controllers with in no time, which else require high loop-shaping expertise. The designed controller has been implemented for a highly uncertain pneumatic servo actuator system.

The paper has been categorised in following sections: Section 2 deals with the background on QFT and MOPSO. Mathematical model of the pneumatic servo actuator system is discussed in Section 3. In Section 4, QFT design performance requirements have been discussed. Section 5 deals with the use of MOPSO for the optimal design of QFT controllers. Results and discussions are in Section 6. In Section 7, level diagrams have been used for the selection of ideal solution from POS. Validation of the designed controller for uncertain system have been done in Section 8 followed by conclusions.

\section{Background}

This section deals with brief outline on the essentials of Quantitative Feedback Theory and multi-objective particle swarm optimization.

\subsection{Quantitative Feedback Theory}

It is essential for the controller to assure quality control over time, but plant ignorance, parameter variation, non-linearity etc. make it obscure. So, to handle such uncertainties' and exert quality control, ample research has been carried out and has led to the foundation of several strong robust control theories of $\mathrm{H} \infty, \mathrm{H}_{2}, \mathrm{LQR}, \mu$-synthesis etc. But real systems exhibit different behavior than the model used in the designing procedure [38] and most of the established theories ignore this fact. So, the modeling of uncertainties' while designing the controller becomes crucial.

In 1960's following the work of Bode, Issac Horowitz introduced a frequency domain controller design technique of Quantitative Feedback Theory (QFT). In QFT, the uncertainty in the plant is depicted using Templates and the performance requirements are translated in the form of Bounds. Bounds act as guide for shaping the open-loop transmission on the Nichols chart at each frequency of interest. QFT has a 2 degree-of-freedom controller structure as in Figure 1. Controller $K(s)$ is in the feedback loop and pre-filter $F(s)$ is placed prior the loop in feed-forward configuration. Controller reduces the closed loop uncertainties and the pre-filter shapes input so that a desired output is obtained. The QFT design procedure is shown in Figure 2. The generalized QFT design procedure is as under:

a. Generate Templates: Based upon the plant's characteristics, a discrete set of frequency points $\omega_{i}$ are chosen for the uncertain plant $\mathrm{G}\left(\mathrm{j} \omega_{\mathrm{i}}\right)$. Templates are plotted on the complex plane for the value sets of the plant, $G\left(j \omega_{i}\right)$ at all design frequencies, $\omega_{i}$.

b. Computation of QFT Bounds: QFT bounds are generated using the system design specifications and templates. Initially a nominal $\mathrm{G}_{0}(\mathrm{j} \omega)$ plant is chosen, which must lie on or above the bounds at each design frequency. Then stability and performance bounds are generated using templates and other frequency domain design requirements. At the end, all the bounds are combined together to design the controller at the loop shaping stage.

c. Loop Shaping of QFT Controller: Phase-Gain loop shaping technique is used to design the controller $\mathrm{K}(\mathrm{j} \omega)$ such that all the bounds are satisfied and the closed loop response of the system is stable.

d. Pre-filter Design: At the final stage, a pre-filter $F(j \omega)$ is designed such that the various time and frequency domain characteristics are satisfied.

\subsection{Multi-objective Particle Swarm Optimization}

Particle swarm optimization (PSO) algorithm mimics the group behavior of bird flocking has been introduced by Kennedy and Eberhart [39] in 1995; and Carlos A. Coello [40] in 2002 extended conventional PSO to handle multiobjective problems. Multi-objective PSO (MOPSO) uses Pareto dominance for determining the flight direction and a global repository of non-dominant elite solutions is maintained and acts as guide for other particles throughout the search process. After each flight, each particle in the swarm updates its flight experience in the global repository.

Initially, flock is initialized and leader is chosen and stored in global repository from the non-dominating particles in the flock. Fitness of all the leaders is evaluated and at each generation for performing a flight, a leader is chosen for each particle. After a successful flight, turbulence operator is applied and fitness the particle is valuated and associated $\boldsymbol{x}_{P B e s t i}$ is updated and a particle replaces its $\boldsymbol{x}_{P B e s t i}$ when a dominant solution is obtained. When all the particles are updated, the set of leaders is also revised followed by fitness evaluation and the process is reiterated till the stopping criteria is met [41].

In PSO, Eq. 1 gives the particle $x_{i}$ at generation $t$ :

$x_{i}(t)=x_{i}(t-1)+v_{i}(t)$

where, $\boldsymbol{v}_{i}(t)$ is the velocity:

$$
\begin{aligned}
& v_{i}(t)=w \times v_{i}(t-1)+C_{1} \times r_{1} \times\left(x_{\text {PBest }_{i}}-x_{i}\right)+C_{2} \times r_{2} \times \\
& \left(x_{\text {GBest }_{i}}-x_{i}\right)
\end{aligned}
$$

where, $\boldsymbol{x}_{P B e s t i}$ is the best solution, $\boldsymbol{x}_{\text {GBest }}$ is the global best solution (Leader), $\boldsymbol{w}$ is the inertia weight, $\boldsymbol{r}_{1} \& \boldsymbol{r}_{2}$ are uniformly distributed random numbers between $[0,1], \boldsymbol{C}_{\boldsymbol{1}}$ \& $\boldsymbol{C}_{2}$ effects the Present and Global bests particles.

The basic formulation of multi-objective problem (for minimization case) is given as, 
$\min _{\theta} \quad J(\theta)=\left[\begin{array}{lll}J_{1}(\theta) & \cdots & J_{m}(\theta)\end{array}\right]$

$g(\theta) \leq 0 \quad g(\theta)=0 \quad \underline{\theta_{i}} \leq \theta_{i} \leq \overline{\theta_{i}} \quad i=\left[\begin{array}{lll}1 & \ldots & n\end{array}\right]$

subject to:

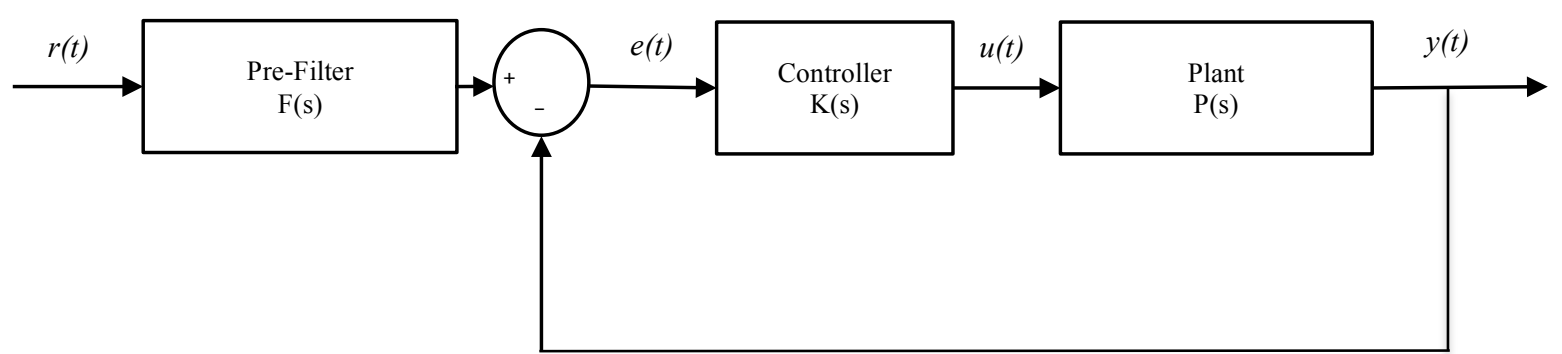

Fig. 1. Block diagram 2 DoF control configuration in QFT

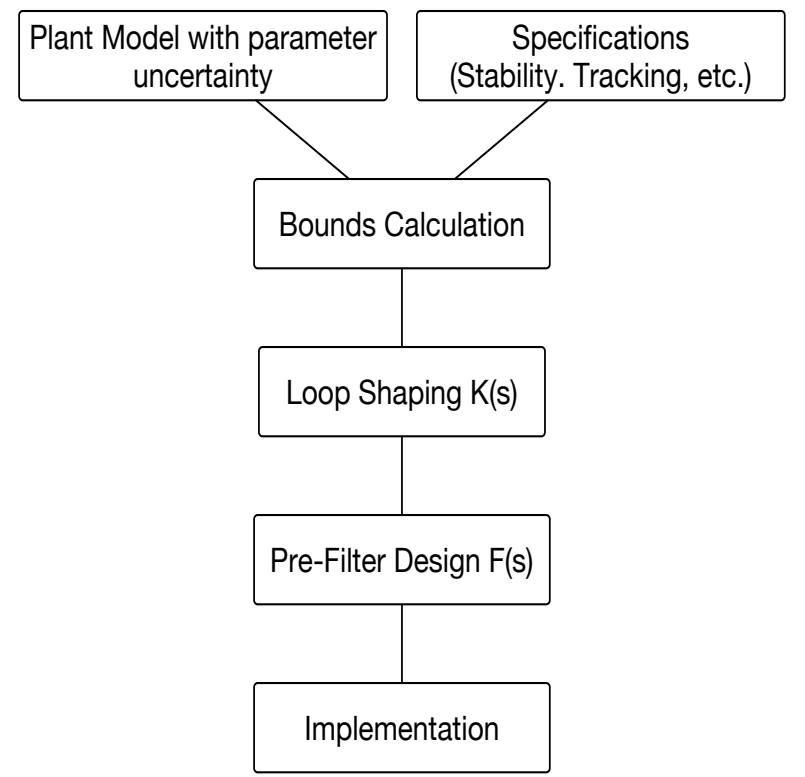

Fig. 2. Flow chart of QFT design procedure.

The pseudo code of MOPSO is given as [41]:

Algorithm 1 Pseudo Code for MOPSO
\begin{tabular}{|c|}
\hline Begin \\
\hline Initialize Swarm \\
\hline Initialize Leaders from the Global Repository \\
\hline Choose Quality Leaders \\
\hline Set Generation $\mathrm{G}=0$ \\
\hline While $G<G_{\text {Max }}$ \\
\hline For each Particle \\
Select Leader \\
\hline During Flight update Position [Equation 7 \\
\& 8$]$ \\
\hline Turbulence \\
\hline Evaluation \\
\hline Update $P_{\text {Best }}$ \\
\hline End \\
\hline Update Leader in Global Repository \\
\hline Determine Quality Leaders \\
\hline Update Generation G $=\mathrm{G}+1$ \\
\hline End \\
\hline Return Repository \\
\hline
\end{tabular}

\section{Mathematical Model of Pneumatic Servo Actuator}

Pneumatic servo actuators are being used widely in the process control and manufacturing industries, as they provide cheaper and reliable solutions to generate force, motion and torque. When a control signal is applied, the pneumatic servo actuator produces the output in the form of displacement (linear/rotational) of load. The electromagnetic force rotates the jet pipe. The motion in the jet pipe is generated by the compressed air, and the movement of load and piston is generated because of the pressure differences in the cylinder cavities. This movement depends on the pressure and flow of the compressed air and the load. A potentiometer is used to measure the displacement of the piston and is feedback to the servo control unit, which also houses power amplifier. Schematic representation of a polarized jet relay is shown in Figure 3 [35].

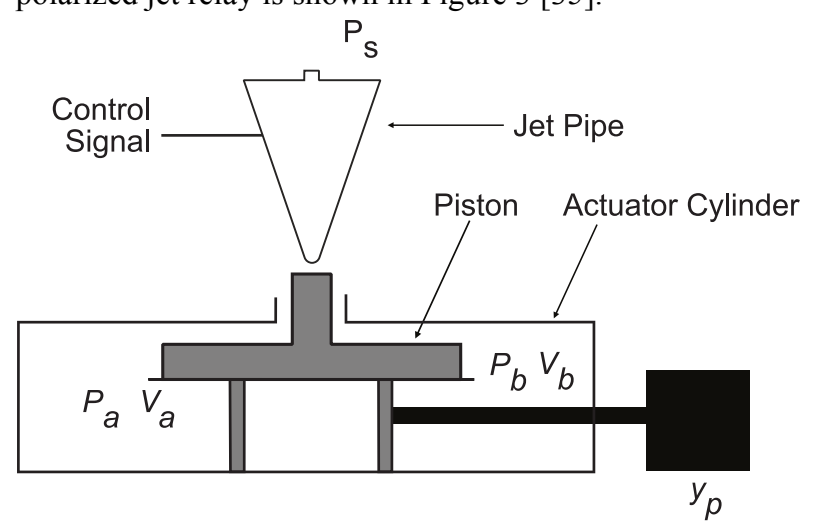

Fig. 3. Schematic representation of pneumatic servo actuator system.

Laws of thermodynamics, motion and fluid dynamics are required to be combined for obtaining the mathematical model of the pneumatic servo actuator. Three major considerations are required:

1. Mass flow rates through valve,

2. Temperature, pressure and volume of the air in the cylinders \&

3. Load dynamics as mentioned in [36] are required to be met.

From Figure 3, the 4-port pneumatic jet pipe valve can be deduced to 2 three-port valves, each on the ends of the cylinder. Here, isothermal behavior of the air is assumed and based upon the ideal gas equations; the equations for mass flow rates can be obtained as [37]: 
$\dot{M}_{a}=\dot{\rho}_{a} V_{a}+\dot{V}_{a} \rho_{a}$

$\dot{M}_{b}=\dot{\rho}_{b} V_{b}+\dot{V}_{b} \rho_{b}$

where, $\dot{M}_{a} \& \dot{M}_{b}$ are the mass flow, $\rho$ is the air density, and $V_{a} \& V_{b}$ is the volume of symmetric chambers $\mathrm{a} \& \mathrm{~b}$ respectively and is given by:

$V_{a}=V_{0}+A_{p} y_{p}$

$V_{b}=V_{b}-A_{P} y_{P}$

where, $V_{o}$ is the air volume of the cylinder at midpoint, $A_{P}$ is the area of piston, and $y$ is the displacement produced.

Using the values of $V_{a} \& V_{b}$ in differentiated Equations 3 $\& 4$ gives,

$$
\begin{aligned}
& \dot{M}_{a}=\frac{1}{\alpha R T_{a}} \dot{P}_{a}\left(V_{0}+A_{p} y_{p}\right)+\frac{1}{\alpha R T_{a}} P_{a} A \dot{y}_{p} \\
& \dot{M}_{b}=\frac{1}{\alpha R T_{b}} \dot{P}_{b}\left(V_{0}-A_{p} y_{p}\right)+\frac{1}{\alpha R T_{b}} P_{b}\left(-A \dot{y}_{p}\right)
\end{aligned}
$$

where, $R$ is the gas constant, $\alpha$ is the specific heat ratio, $T_{a} \&$ $T_{b}$ is the temperature in the symmetric chambers $a \& b$ respectively and $P_{a} \& P_{b}$ is the pressure in the symmetric chambers $a \& b$ respectively.

The overall performance of the piston is governed by load dynamics, so Equation 7 \& 8 becomes:

$$
\begin{aligned}
& \dot{P}_{a}=\frac{\alpha R T_{b}}{\left(V_{0}+A_{p} y_{p}\right)} \dot{M}_{a}-\frac{\alpha P_{a} A_{p}}{\left(V_{0}+A_{p} y_{p}\right)} \dot{y}_{P} \\
& \dot{P}_{b}=\frac{\alpha R T_{b}}{\left(V_{0}-A_{p} y_{p}\right)} \dot{M}_{b}-\frac{\alpha P_{a} A_{p}}{\left(V_{0}-A_{p} y_{P}\right)} \dot{y}_{P}
\end{aligned}
$$

$$
\ddot{y}_{P}=\frac{A_{P}}{M} P_{a}-\frac{A_{P}}{M} P_{b}-\frac{1}{M} F_{L}-\frac{1}{M} F_{f}
$$

The equations for control valve can be obtained as:

$$
\dot{M}_{a}=K_{v} \frac{P_{s}}{2} u \text { and } \dot{M}_{b}=-K_{V} \frac{P_{s}}{2} u
$$

where, $M$ is the mass of the load, $F_{L}$ is the disturbing force, $F_{f}$ is the force of friction, $K_{V}$ is coefficient of the valve, $P_{s}$ is the applied pressure, and $u$ is the input electrical signal.

Using the equation 12 in Equations 9 \& 10; and taking the Laplace transformations of Equation 9, 10 and 11; and linearizing the actuator and valve characteristics at the operating point, a $4^{\text {th }}$ order open loop transfer function has been obtained as [35]:

$$
G(s)=\frac{2 K \frac{\alpha R T A_{P}}{M V_{0}}}{s\left(\tau_{v} \cdot s+1\right)\left(s^{2}+\left(\frac{f}{M}-\frac{\alpha R T L_{a}}{M V_{0}}\right) \cdot s+\left(\frac{2 \alpha(A p)^{2} P_{i}}{M V_{0}}-\frac{\alpha R T L_{a} A_{P} f}{M V_{0}}\right)\right)}
$$

here, $\tau_{v}$ is the valve time constant, $f$ is the coefficient of viscous friction, $L_{a}$ is chosen to be small as compared to other system parameters and in case of chocked flow $L_{a}=0$; and bounding the chocked flow and unchecked flow rate by chocked flow rate leads to the maximum mass flow rate.

\subsection{Uncertain model of pneumatic servo actuator}

In industrial applications, air pressure is kept low from the safety point of view; which results in narrow bandwidth of the system. Hence it becomes tough to design high performance position control actuators. Also because of the limited pressure supplies the actuator stiffness is very limited and in case of varying loads it becomes very difficult to assure quality control. Non-linear behavior of flow valves and parametric uncertainties' leads to time varying dynamics which makes it difficult for the controller to assure quality control over time and this results in time varying outputs. Table 1 shows the nominal values of the parameters and the range of uncertainty. Figure 4 shows the open loop step response and Bode plot of the uncertain system.

Table 1 Nominal parameters and the range of parametric uncertainty.

\begin{tabular}{l|l|l|l|l}
\hline \multicolumn{2}{c|}{ Parameters } & Nominal Value & \multicolumn{1}{c}{ Range } & \multicolumn{1}{c}{$\begin{array}{c}\text { Degree of } \\
\text { Uncertainty }\end{array}$} \\
\hline Piston Area & $A_{p}\left(\mathrm{~m}^{2}\right)$ & - & - \\
Gas Constant & $R(\mathrm{~J} / \mathrm{kg} . \mathrm{K})$ & 0.005 & - & - \\
Air Volume & $V_{o}\left(\mathrm{~m}^{3}\right) \times 10^{4}$ & 287 & {$[1.5,4]$} & {$[-40,60 \%]$} \\
(Piston at midpoint) & $P_{i}(\mathrm{bar})$ & 2.5 & {$[3,4]$} & {$[0,33.3 \%]$} \\
Chamber Pressure & $M(\mathrm{~kg})$ & 3 & {$[0.1,5]$} & {$[-90,500 \%]$} \\
Mass of the Load & 1 & {$[50,80]$} & {$[-16.67,33.33 \%]$} \\
Coefficient of & $f(\mathrm{~N} . \mathrm{s} / \mathrm{m})$ & 60 & {$[3.2,3.4]$} & {$[-5.88,0 \%]$} \\
Damping & $K(\mathrm{~kg} / \mathrm{s} . \mathrm{V}) \times 10^{3}$ & 3.4 & - & - \\
Valve Gain & $T(\mathrm{~K})$ & 293.15 & - & - \\
Air Temperature & $\alpha$ & 1.4 & - & - \\
Specific Heat Ratio & $K_{p}(\mathrm{~V} / \mathrm{m})$ & 400 & \\
Potentiometer Constant & &
\end{tabular}



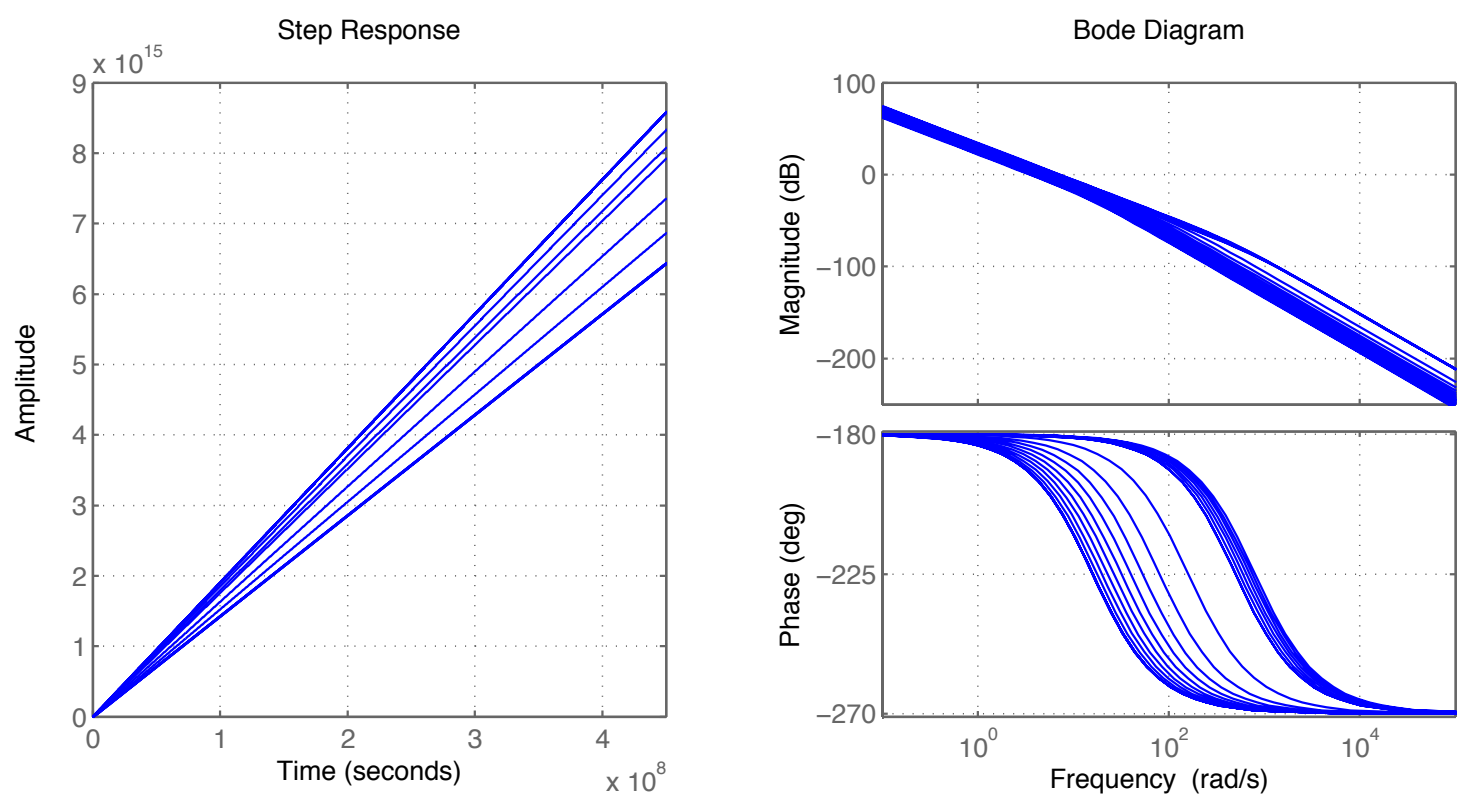

Fig. 4. Time and frequency domain response characteristics of the open-loop pneumatic servo actuator system with parametric uncertainties.

\section{QFT Controller Design Requirements}

The QFT performance objectives of robust stability, tracking performance and sensitivity, which have been used in the design process, are discussed in this section.

\subsection{Robust Stability}

Minimization of the peak magnitude of the closed loop frequency response of the systems ensures robust stability, and is given as:

$$
\left|\frac{L(j \omega)}{1+L(j \omega)}\right| \leq \delta_{1}
$$

where, $L(j \omega)=K(j \omega) G_{0}(j \omega)$ is the nominal open loop transfer function and $\delta_{1}$ is the constant and is obtained from the desired gain and phase margins.

Robust stability must be satisfied at each design frequency. For designing the controller $K(j \omega)$, frequency range is selected as $\omega=[0.4,0.8,1.2,1.7,2.1,10,25,50$, $100,200] \mathrm{rad} / \mathrm{sec}$. The maximum variation of magnitudes $\delta_{\mathrm{P}}\left(j \omega_{i}\right)$ at each design frequency $\omega_{i}$ for the uncertain plant $G(j \omega)$ is given by Equation 15 and difference between the tracking bounds is given by $\delta_{\mathrm{R}}\left(j \omega_{i}\right)$ and is expressed by Equation 16.

$$
\begin{aligned}
& \delta_{P}\left(j \omega_{i}\right)=\left|G\left(j \omega_{i}\right)\right|-\left|G_{0}\left(j \omega_{i}\right)\right| \\
& \delta_{R}\left(j \omega_{i}\right)=\left|T_{U}\left(j \omega_{i}\right)\right|-\left|T_{L}\left(j \omega_{i}\right)\right|
\end{aligned}
$$

Equation 17 gives the maximum closed loop magnitude variation because of the parametric uncertainty:

$$
\delta_{L}\left(j \omega_{i}\right)=\left|\frac{G\left(j \omega_{i}\right) \cdot K\left(j \omega_{i}\right)}{1+G\left(j \omega_{i}\right) \cdot K\left(j \omega_{i}\right)}\right|-\left|\frac{G_{0}\left(j \omega_{i}\right) \cdot K\left(j \omega_{i}\right)}{1+G_{0}\left(j \omega_{i}\right) \cdot K\left(j \omega_{i}\right)}\right|
$$

For achieving robust stability, $\delta_{\mathrm{L}}\left(j \omega_{i}\right)$ must be minimized and its constraint is given by Equation 18 .

$\delta_{L}\left(j \omega_{i}\right) \leq \delta_{R}\left(j \omega_{i}\right)$

\subsection{Tracking Performance}

The desired time domain characteristics of rise time, settling time, overshoot \%age is declared on the onset of the design process. These tracking ratios act as guidelines for shaping the time and frequency domain characteristics of the closed loop system. The optimal response must lie within these bounds. The upper and lower bounds $\mathrm{T}_{\mathrm{U}}(\mathrm{j} \omega) \& \mathrm{~T}_{\mathrm{L}}(\mathrm{j} \omega)$ are given by equation $19 \& 20$ and their time \& frequency domain response is shown in Figure 5. Based upon the system design requirements, $T_{L}(j \omega)$ has over-damped characteristics with a rise time of $0.5714 \mathrm{sec}$, settling time of $1.065 \mathrm{sec}$ and maximum overshoot of $0 \%$. Whereas $T_{U}(j \omega)$ has a rise time of $0.0852 \mathrm{sec}$, settling time of $0.8854 \mathrm{sec}$ and maximum overshoot of $36.41 \%$.

$$
\begin{aligned}
& T_{U}(j \omega)=\frac{400000}{s^{4}+174 \cdot s^{3}+8680 \cdot s^{2}+132000 \cdot s+400000} \\
& T_{L}(j \omega)=\frac{1300 \cdot s+6500}{s^{3}+110 \cdot s^{2}+1065 \cdot s+6500}
\end{aligned}
$$

Equation 21 gives QFT tracking performance bound.

$$
\left|T_{L}(j \omega)\right| \leq\left|\frac{L(j \omega)}{1+L(j \omega)}\right| \leq\left|T_{U}(j \omega)\right|
$$

Minimization of $\delta_{\mathrm{F}}\left(j \omega_{i}\right)$ has been carried out to satisfy the tracking bounds. $\delta_{\mathrm{F}}\left(j \omega_{i}\right)$ is given as:

$$
\delta_{F}\left(j \omega_{i}\right)=\left|\frac{T_{U}\left(j \omega_{i}\right)-T_{L}\left(j \omega_{i}\right)}{2}\right|-\left|\frac{G\left(j \omega_{i}\right) \cdot K\left(j \omega_{i}\right)}{1+G\left(j \omega_{i}\right) \cdot K\left(j \omega_{i}\right)}\right|
$$

\subsection{Sensitivity}

To insure the robustness of the designed system to external disturbances, minimization of the sensitivity function over a range of $\omega \leq 10 \mathrm{rad} / \mathrm{sec}$ has been considered. Equation 23 gives the design bound on sensitivity such that its maximum value at each design frequency is less than unity.

$\left|S\left(j \omega_{i}\right) \cdot W_{P}\left(j \omega_{i}\right)\right|<1$

where, 


$$
S\left(j \omega_{i}\right)=\frac{1}{1+G\left(j \omega_{i}\right) K\left(j \omega_{i}\right)}
$$

Equation 24 is the performance weighting function $W_{p}(j \omega)$ and has been chosen as:

$W_{P}(j \omega)=\frac{\frac{s}{\sqrt{M_{S}}}+w_{b}}{s+w_{b} \sqrt{\varepsilon}}$

where, $M_{s}$ is the maximum peak magnitude of the $S(j \omega)$ and is taken as $4, w_{b}$ is minimum allowable bandwidth and is

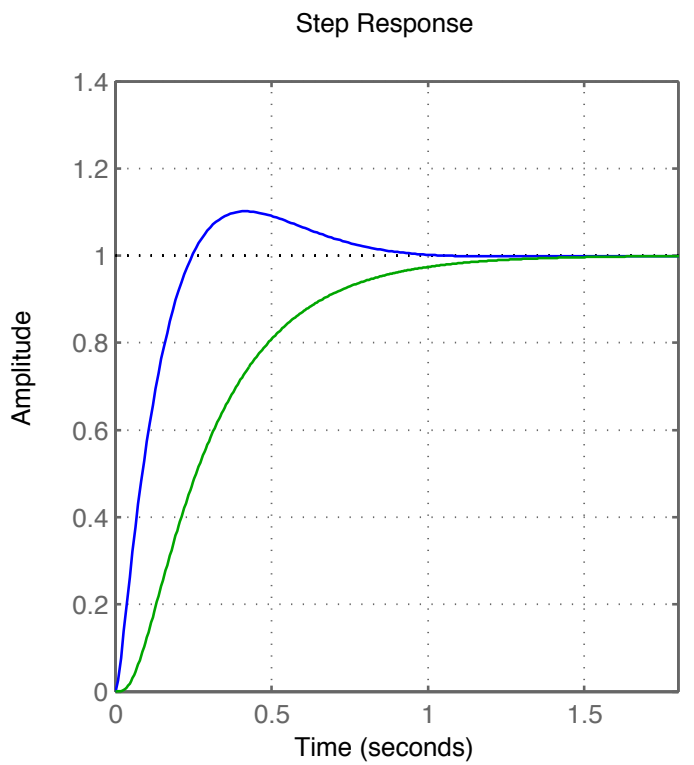

Fig. 5. Upper and lower tracking bounds in time and frequency domain.

\section{Optimisation based Design of QFT Controllers using MOPSO}

The automatic loop shaping of the QFT controller has been posed as a multi-objective optimization problem, such that the desired criterias of robust stability, tracking performance and senstivity are satisifed. Multi-objective particle swarrm optimization has been used for obtaining the optimal values of the controller gains $\left[K_{g}, z_{1}, z_{2}, p_{1}, p_{2}\right]$ by minimizing the proposed objective function $J$ given by Equation 26 .

Find $K=\left[\begin{array}{c}K_{G} \\ z_{1} \\ z_{2} \\ p_{1} \\ p_{2}\end{array}\right]$, which minimizes, $J=\left[\begin{array}{c}\delta_{L}\left(j \omega_{i}\right) \\ \delta_{F}\left(j \omega_{i}\right) \\ J_{S}\end{array}\right]$

A fixed structure controller given by Equation 27 has been considered for the design process. Minimization of $\boldsymbol{J}$, lessens the variation in response of the closed loop system in presence of parametric uncertainties, ensures proper tracking performance and disturbance rejection at each frequency of interest.

$K(s)=K_{G} \frac{\left(z_{1} \cdot s+1\right)\left(z_{2} \cdot s+1\right)}{\left(p_{1} \cdot s+1\right)\left(p_{2} \cdot s+1\right)}$

\section{Results and Discussions}

The proposed objective function $\boldsymbol{J}$ has been minimized using multi-objective particle swarm optimization for finding the taken as $10 \mathrm{rad} / \mathrm{sec}$ and $\boldsymbol{e}$ is taken as 0.01 . Using these values, $W_{p}(j \omega)$ is given as:

$W_{P}(j \omega)=\frac{s+20}{2 \cdot s+2}$

For the closed loop uncertain system to satisfy the desired disturbance rejection criterion, the minimization of sensitivity performance index given in Equation 25 has been considered.

$J_{S}=\left|S\left(j \omega_{i}\right) \cdot W_{P}(j \omega)\right|$

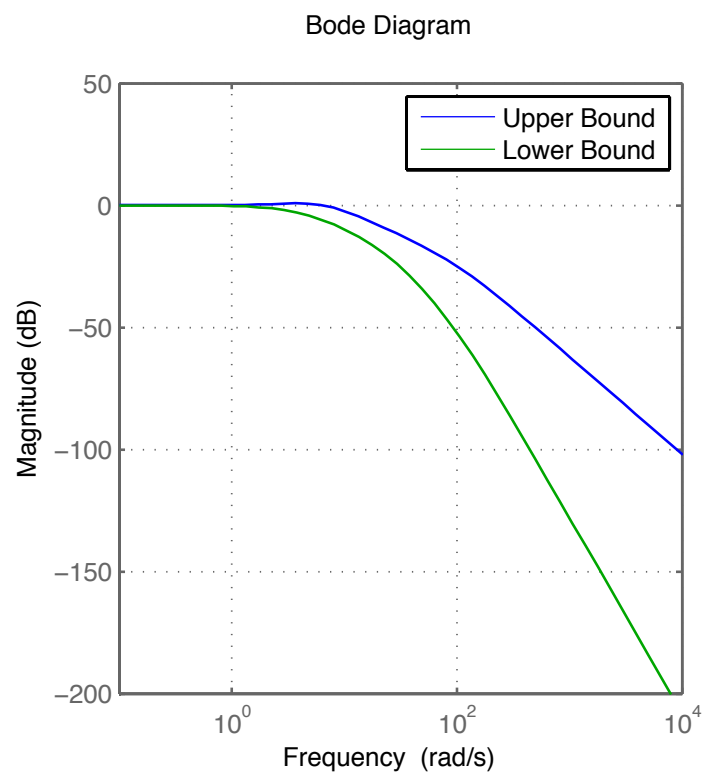

optimal controller coefficients given by Equation 27. In the QFT design procedure the nominal plant has been chosen from the parameters given in Table 1 and is given by Equation 28. Equation 29 gives the compensated nominal open loop transfer function $L_{0}(s)$.

$G_{0}(s)=\frac{1602}{s^{3}+60 s^{2}+84 \times 10^{-6} s}$

$L_{0}(s)=K_{G} \frac{\left(z_{1} \cdot s+1\right)\left(z_{2} \cdot s+1\right)}{\left(p_{1} \cdot s+1\right)\left(p_{2} \cdot s+1\right)} \cdot \frac{1602}{s^{3}+60 s^{2}+84 \times 10^{-6} s}$

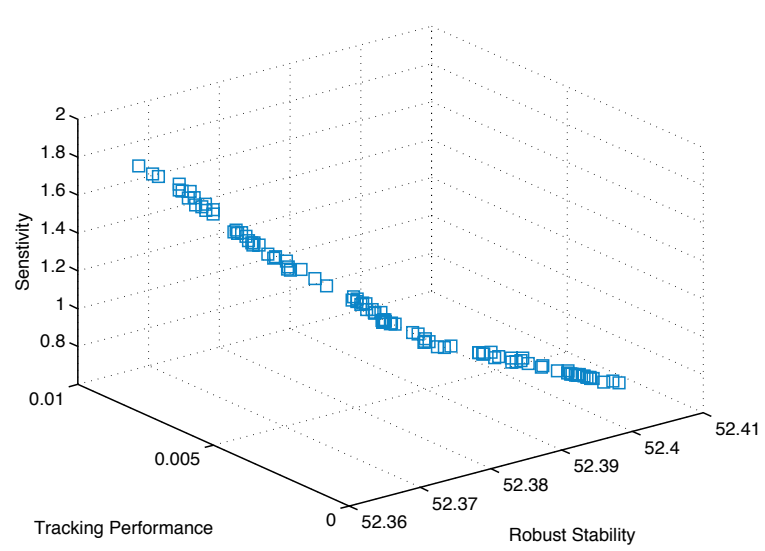

Fig. 6. Pareto front obtained between various controller design objectives

After performing several trials, the MOPSO parameters, which have been selected for carrying out, the design 
process are given in Table 2. The automatic loop shaping of QFT controller using MOPSO has been performed in Matlab with above-mentioned parameters. At the end of the optimization process, a set of Pareto optimal solutions (POS) has been obtained. Each solution in the Pareto optimal set is an optimal solution, such that no further improvement can be achieved on one optimization objective without the
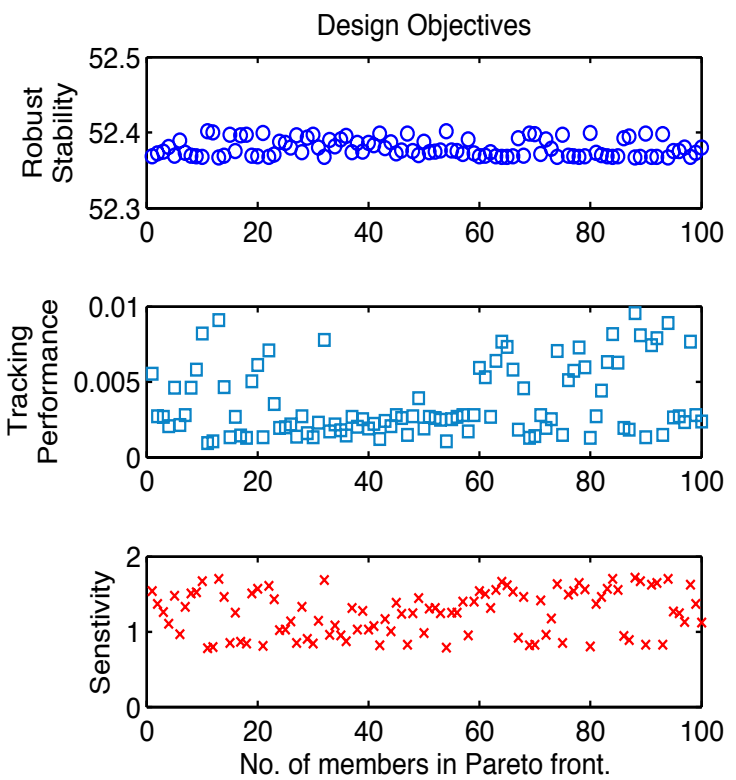

Fig. 7. Pareto optimal set of controller parameter obtained. Step Response

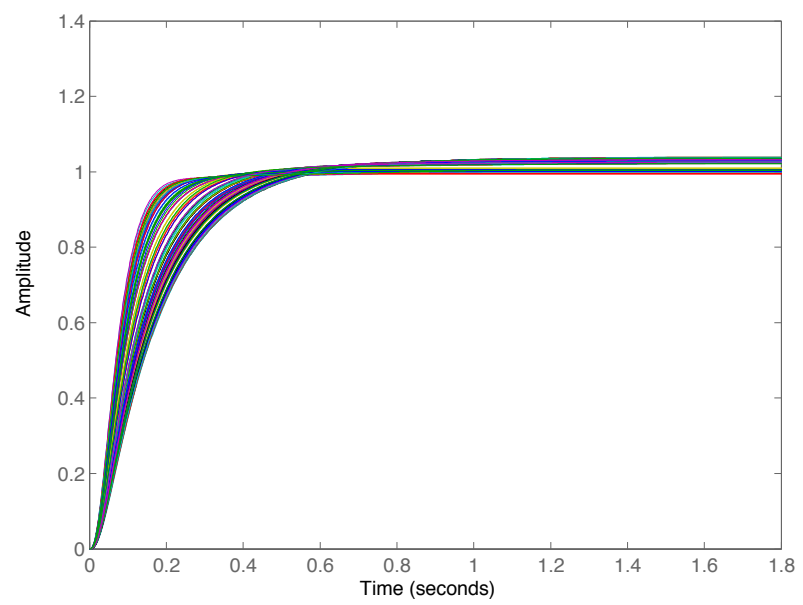

Fig. 8. Step response of the closed loop system with all the controller parameters. sacrificing of the remaining objectives. Figure 6 gives the visualization of the Pareto front obtained. The obtained solutions have been show in in Figure 7. The step response and Bode plot of the closed loop system with the controller parameters obtained in POS is shown in Figure $8 \& 9$.
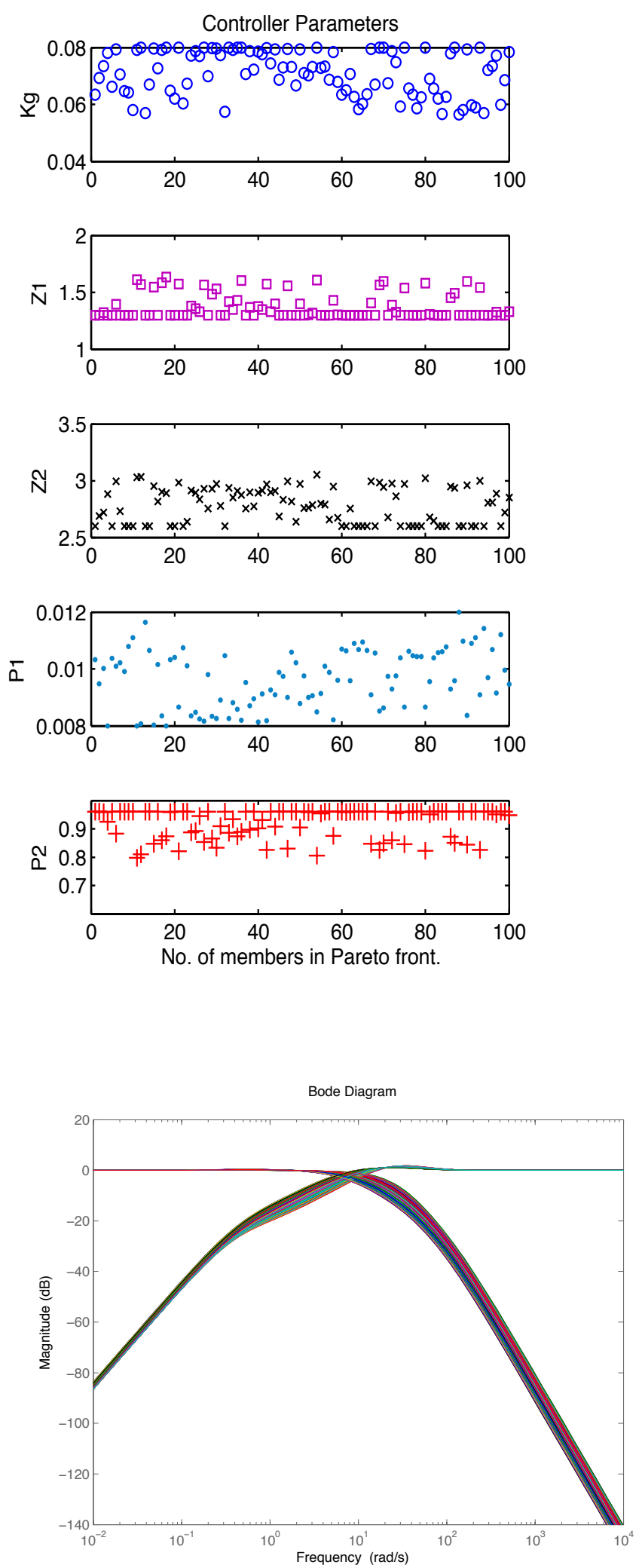

Fig. 9. Magnitude plot for the frequency response of the closed loop system with all the controller parameters. 
Table 2. Multi-objective Particle Swarm Optimization Algorithm Parameters Considered in Design Process.

\begin{tabular}{l|l}
\hline MOPSO Parameters & Value \\
\hline Swarm Size & 100 \\
Repository Size & 100 \\
Inertia Weight & 0.729 \\
Inertia Weight Damping Ratio & 1 \\
Personal Learning Coefficient & 1.4962 \\
Global Learning Coefficient & 1.4962 \\
Leader Selection Pressure Parameter $(\beta)$ & 2 \\
Extra Repository Member Selection Pressure & 2 \\
$(\gamma)$ & 100 \\
Maximum Iterations & \\
\hline
\end{tabular}

\section{Selection of Ideal Solution from POS using Level Diagrams}

As all the controller coefficients are Pareto optimal, the decision maker has to choose a trade-off amongst the design objectives to choose the best set of controller parameters. The difficulty arises in graphically analyzing the Pareto front for $m$-dimensional problems. Generally, scatter matrices and parallel coordinate representations are used, but they provide very compact representation of the data and the results looses clarity. The paper, explores the use of level diagrams for visualizing the Pareto front and Pareto set for choosing the ideal controller parameters [42].

Level diagrams categorizes the Pareto front $J_{p}^{*}$ intuitively. Each design objective is $J_{q}(\theta)$ is normalized and is given by Equation 30 .

$\widehat{J_{q}}(\theta)=\frac{J_{q}(\theta)-J_{q}^{\min }}{J_{q}^{\max }-J_{q}^{\min }} \quad q \epsilon[1 \quad \ldots \quad m]$

where,

$J^{\min }=[\underbrace{\min }_{J_{1}(\theta) \in J_{p}^{*}} J_{1}(\theta) \quad \cdots \quad \underbrace{\min }_{J_{m}(\theta) \in J_{p}^{*}} J_{m}(\theta)]$

$J^{\max }=[\underbrace{\max }_{J_{1}(\theta) \in J_{p}^{*}} J_{1}(\theta) \quad \cdots \quad \underbrace{\max }_{J_{m}(\theta) \in J_{p}^{*}} J_{m}(\theta)]$

$P$-norm $\|\hat{J}(\theta)\|_{p}$ of each normalized objective $\hat{J}(\theta)$ is evaluated for calculating the distance to the ideal solution $\boldsymbol{J}^{\text {ideal }}=\boldsymbol{J}^{\text {min }}$. Most commonly norms are 1-norm, 2-norm and $\infty$-norm; and are given as:

$$
\begin{aligned}
& \|\hat{J}(\theta)\|_{1}=\sum_{q=1}^{m} \hat{J}_{q}(\theta) \\
& \|\hat{J}(\theta)\|_{2}=\sum_{q=1}^{m}\left(\hat{J}_{q}(\theta)\right)^{2} \\
& \|\hat{J}(\theta)\|_{\infty}=\max \left[\hat{J}_{q}(\theta)\right]
\end{aligned}
$$

Level diagram offers a 2-dimensional representation of every design objective $\left(J_{q}(\theta) \quad\|\hat{J}(\theta)\|_{p}\right)$ and the decision $\operatorname{variable}\left(\begin{array}{ll}\theta_{l} & \|\hat{J}(\theta)\|_{p}\end{array}\right)$ in ordered pairs. So, a given solution will have same value along the $y$-axis for all the graphs. This makes it easier for the characterization of the inclination of the Pareto front and the comparison of solutions with respect to the selected norm.

In this work, $\|\cdot\|_{2}$ (2-norm) has been considered for the estimation of the best controller parameters. Level diagrams for the QFT design objectives is shown in Figure 10 and for QFT controller parameters in Figure 11. The selecting the best set of controller parameters, the point with minimum value on the level diagrams (marked as Green Square) has been chosen. The controller parameters corrosponding to the chosen point on the level diagram are shown in Table 3.
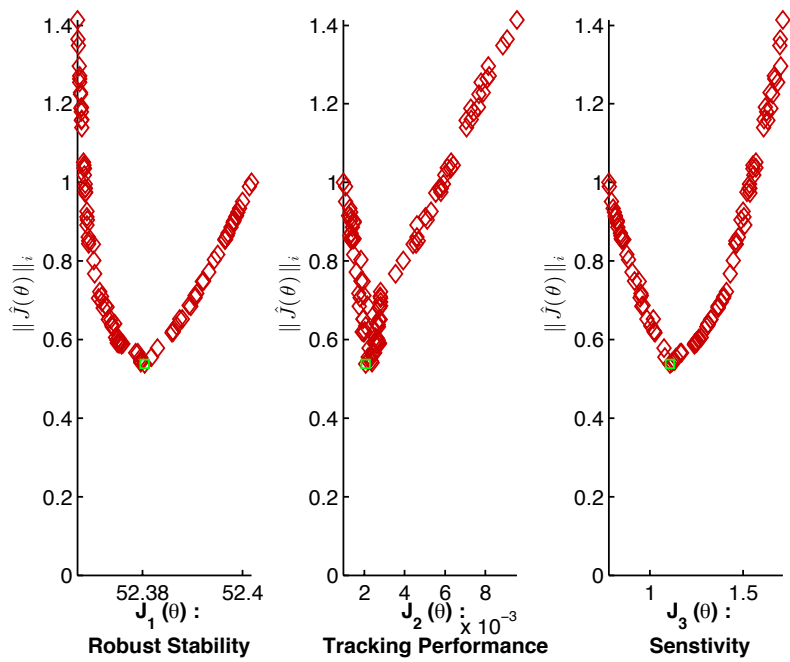

Fig. 10. Level diagrams for the QFT design objectives.
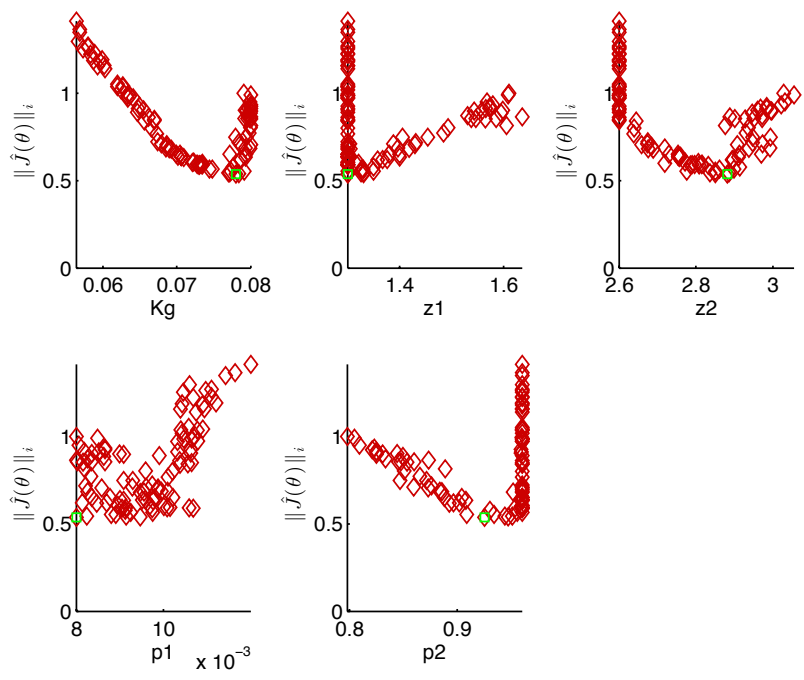

Fig. 11. Level diagrams for the QFT controller parameters.

Table 3. Best controller coefficients and their respective QFT objective values.

\begin{tabular}{l|l|l|l|l|l|l|l|l}
\hline $\begin{array}{l}\text { Control } \\
\text { ler } \\
\begin{array}{l}\text { Coeffici } \\
\text { ents }\end{array}\end{array}$ & $\delta_{L}\left(j \omega_{i}\right)$ & $\delta_{F}\left(j \omega_{i}\right.$ & $J_{s}$ & $\mathrm{~K}_{\mathrm{g}}$ & $\begin{array}{l}\mathrm{Z} \\
1\end{array}$ & $\mathrm{Z}_{2}$ & $\mathrm{P}_{1}$ & $\mathrm{P}_{2}$ \\
\hline Values & 52.38 & $\begin{array}{l}0.002 \\
07\end{array}$ & $\begin{array}{l}1.1 \\
07\end{array}$ & $\begin{array}{l}0.78 \\
019\end{array}$ & $\begin{array}{l}1 . \\
3\end{array}$ & $\begin{array}{l}2.88 \\
15\end{array}$ & $\begin{array}{l}0.0 \\
08\end{array}$ & $\begin{array}{l}0.92 \\
527\end{array}$ \\
\hline
\end{tabular}

The closed loop response of the selected controller for the pneumatic servo actuator system (nominal case) has been shown in Figure 12 along with the magnitude plot for the frequency response of the system in Figure 13. 


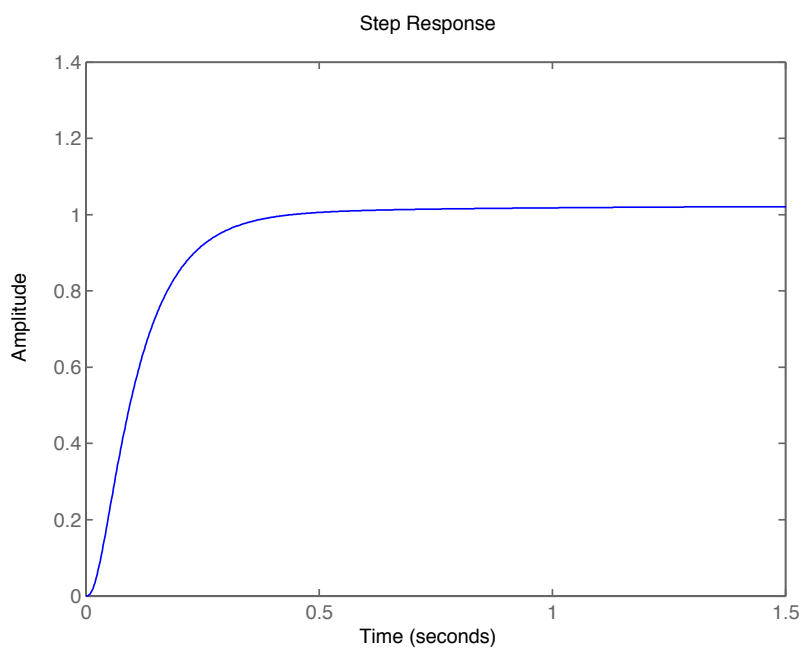

Fig. 12. Step response of the closed loop system for nominal plant case.

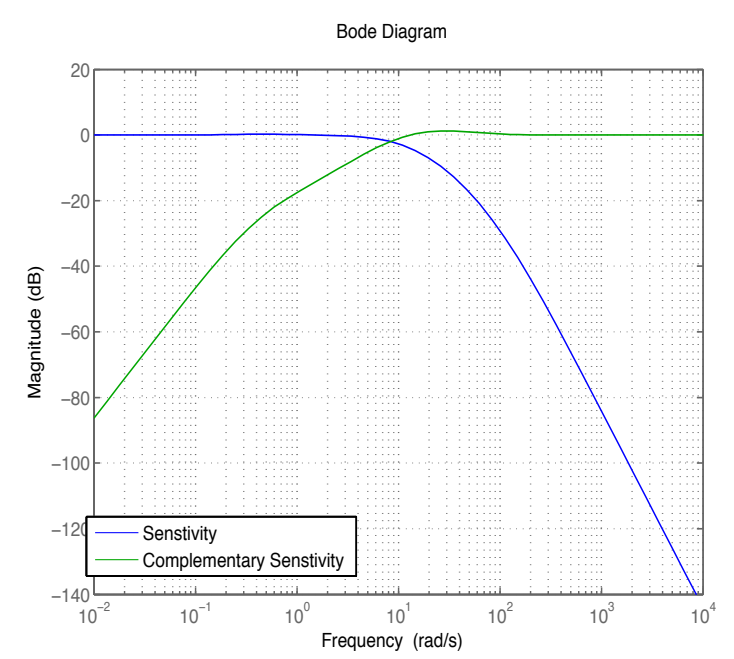

Fig. 13. Magnitude plot for the frequency response of the closed loop system for nominal plant case.

The nominal open loop transfer function $\mathrm{L}_{0}(\mathrm{~s})$ has been visualized on the Nichols chart in Figure 14 and the plot for the disturbance rejection at the input of the plant is shown in Figure 15. In Table 4 various time and frequency domain performance characteristics for the nominal and worst-case response are given.

Table 4. Time domain performance of the closed loop system for the nominal and worst-case plant.

\begin{tabular}{l|l|l}
\hline \multicolumn{1}{c|}{$\begin{array}{c}\text { Time Domain Performance } \\
\text { Index }\end{array}$} & \multicolumn{1}{|c}{$\begin{array}{c}\text { Nominal } \\
\text { System }\end{array}$} & \multicolumn{1}{c}{$\begin{array}{c}\text { Worst Case } \\
\text { Response }\end{array}$} \\
\hline Rise Time & 0.1963 secs. & 0.1345 secs. \\
Settling Time & 0.3613 secs. & 0.4613 secs. \\
Overshoot Percentage & $0.287 \%$ & $12.92 \%$ \\
Gain Margin & 17.542 & 9.7703 \\
Phase Margin & 170.259 & 95.315 \\
\hline
\end{tabular}

\section{Design Validation}

The validation of the designed optimal QFT controller is must, such that it satisfies the desired performance criteria over a range of plant parametric uncertainty. In this paper, we consider two cases, one for the complete parametric uncertainty as given in Table 1 and other case only for the varying actuator loads.

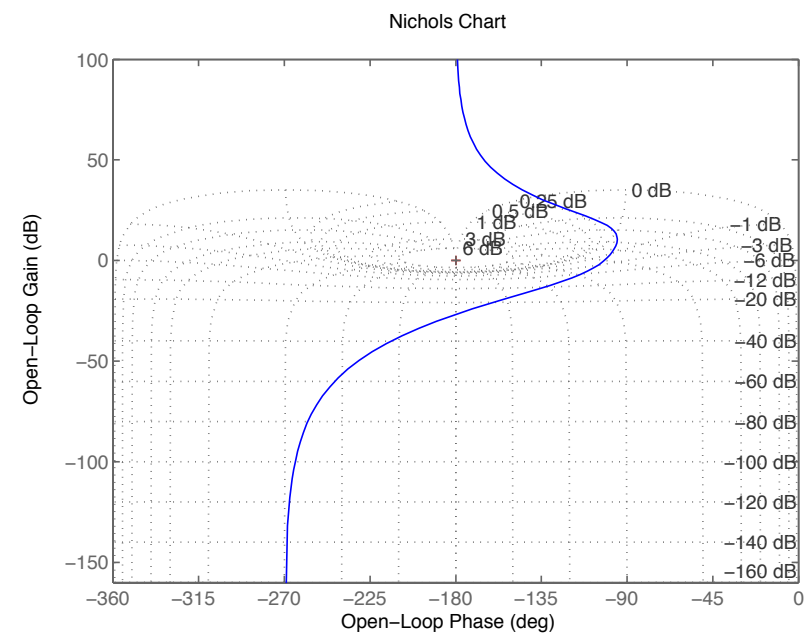

Fig. 14. Nichols chart for the nominal open loop system.

Step Response

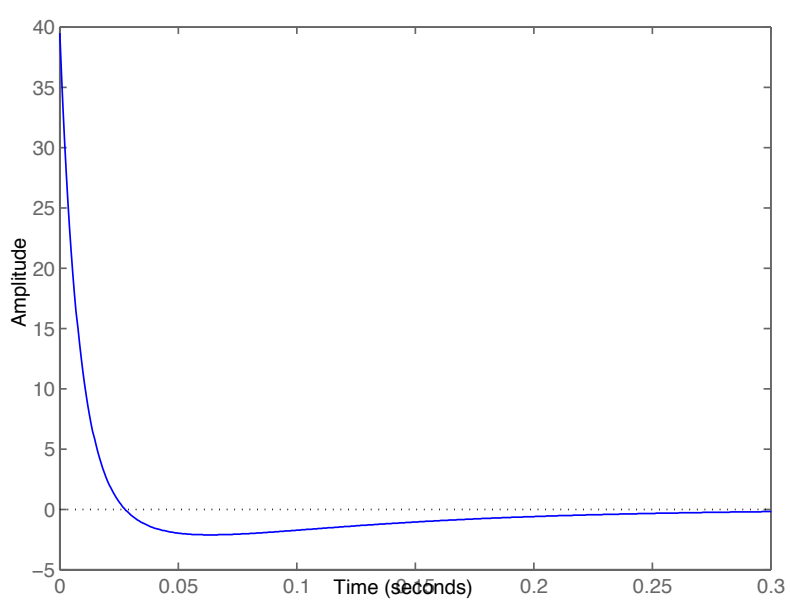

Fig. 15. Plot for input disturbance rejection for nominal plant case.

\subsection{For parametric uncertainties}

The designed QFT controller has been implemented for the pneumatic servo actuator system with parametric uncertainties as in Table 1. Figure 16 shows the worst-case step response of the closed loop system with uncertainties; and the magnitude plot for the frequency response of the system is shown in Figure 17. From both these figures, it can be seen that the designed controller produces a satisfactory response and in the limits of design requirements.

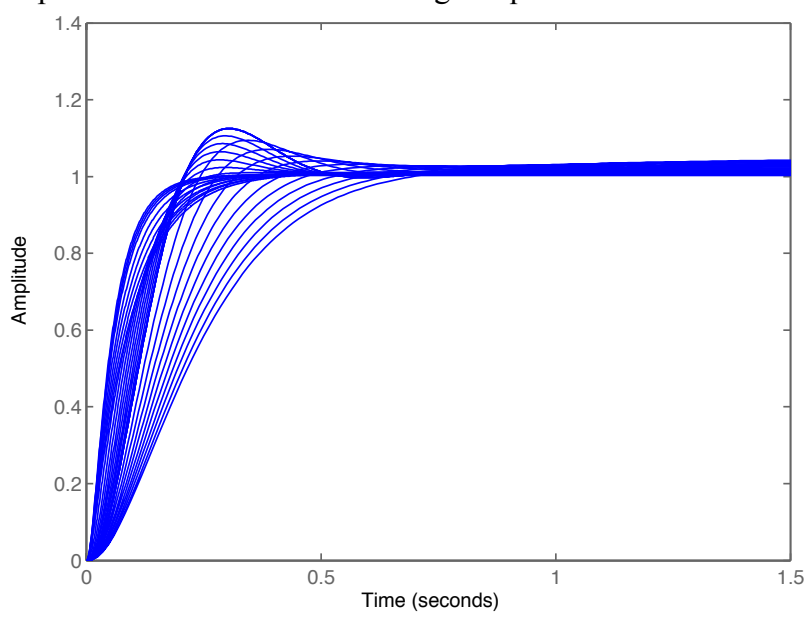

Fig. 16 Worst-case step response of the closed loop system for servo pneumatic servo actuator system. 


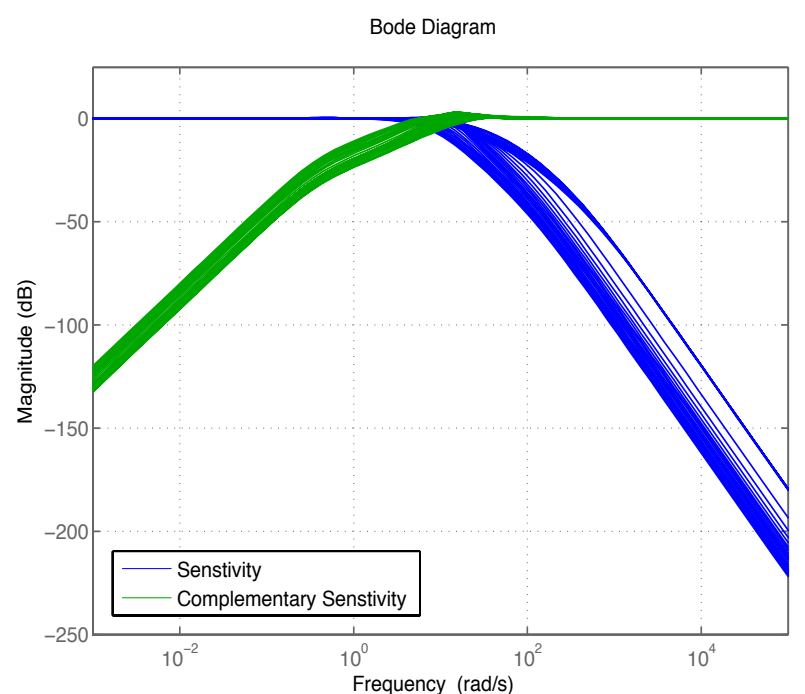

Fig. 17. Magnitude plot for the worst-case frequency response of the closed loop system for servo pneumatic servo actuator system.

The plot for input disturbance rejection in case of parametric uncertainties is shown in Figure 18 followed by the Nichols chart for the open loop transmission for plant's worst case in Figure 19.

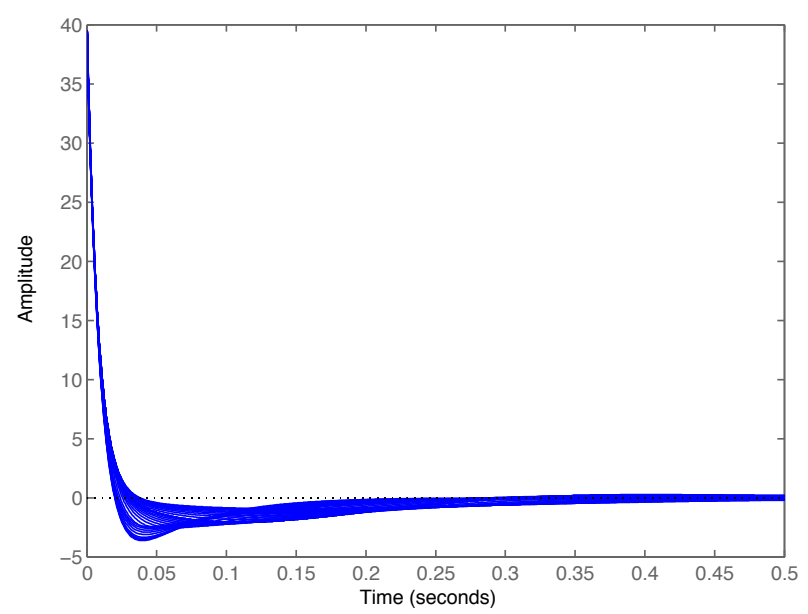

Fig. 18. Input disturbance rejection for the worst-case of the closed loop system for servo pneumatic servo actuator system.

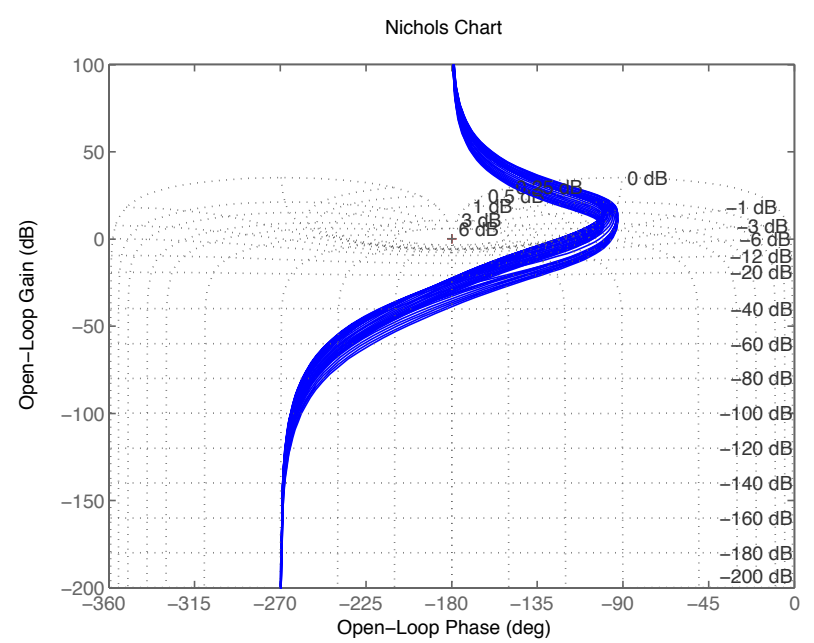

Fig. 19. Nichols chart for the worst-case open loop transmission for servo pneumatic servo actuator system.

\subsection{For varying loads}

As the actuator stiffness is very limited because of the limited air pressure supply. So, in case of varying loads, the actuator may not present a desired response. To check the system's performance in case of varying load, a variation of $-90 \%$ to $500 \%$ (against nominal value) has been considered. Figure $20 \& 21$ shows the step and frequency response of the closed loop system and it can be seen from the figures even in presence of such high uncertainty in the system, the compensated system produces a stable response.

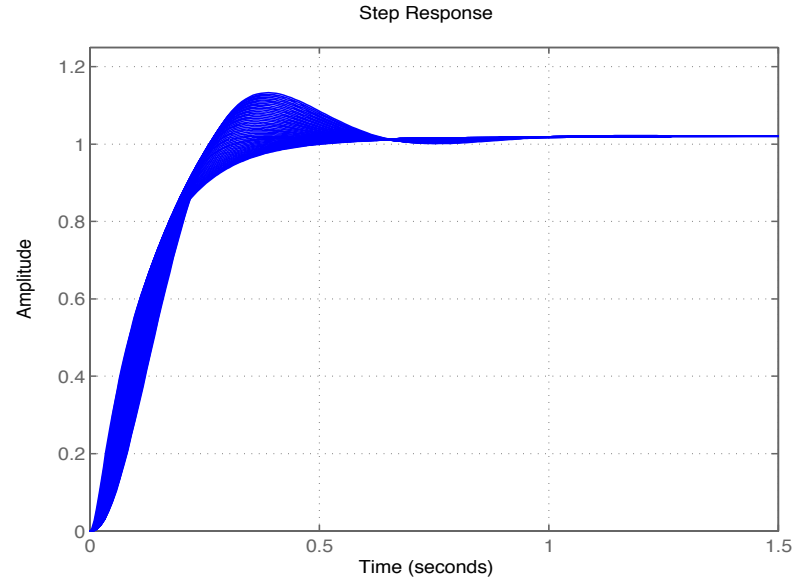

Fig. 20. Step response of the closed loop pneumatic servo actuator system with varying load with best set of controller coefficients.

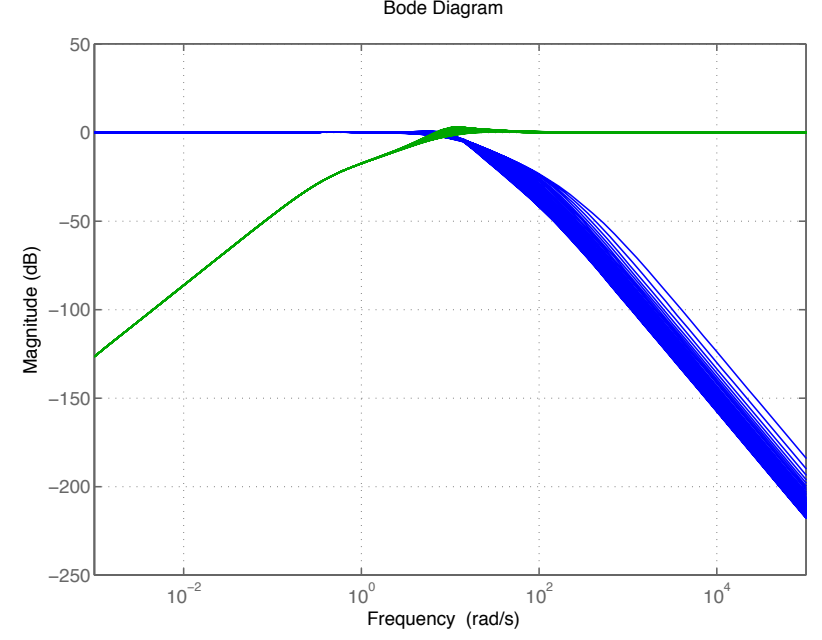

Fig. 21. Frequency response of the closed loop pneumatic servo actuator system with varying load with best set of controller coefficients.

\section{Conclusions}

This paper presents the automation of the loop-shaping step of the synthesizing QFT controller for a highly uncertain pneumatic servo actuator system. Predominantly the loop shaping is performed manually on Nichols chart and requires considerable loop shaping experience, and still there is no guarantee that an optimal controller has been designed. In this paper, the automatic synthesis of the QFT controller has been posed as a multi-objective problem and multi-objective variant of particle swarm optimization has been used for minimizing proposed cost function. This automates the loopshaping procedure and gives flexibility to the designer to pre-specify the controller structure and order. The use of MOPSO facilitate the designer with Pareto optimal set of solutions, which provide even more flexibility to the designer to choose controller coefficients based upon the desired tradeoff among several objectives. At the decision making step for choosing the best parameters from the 
Pareto optimal set, level diagrams has been used for intuitively finding out the ideal solution. From the results obtained in this paper, it can be clearly seen that the designed QFT controller for pneumatic servo actuator offers a robust response in presence of parametric uncertainties and varying load. Thus ensuring quality of control, quality of the product and well as the systems' safety and integrity.

\section{References}

1. Bars R, Colaneri P, de Souza CE, Dugard L, Allgower F, Kleimenov A, Scherer C. Theory, algorithms and technology in design of control systems. Annu. Rev. Control 2006; 30: 19-30.

2. Veselý V. Robust Control Methods a Systematic Survey. J. Electr. Eng. 2013; 64(1): 59-64.

3. Bode HW. Network Analysis and Feedback Amplifier Design, New York, USA: Van Nostrand, 1945.

4. Horowitz IM. Quantitative Feedback Design Theory (QFT). Boulder, USA: QFT Publications, 1993.

5. Bhattacharyya SP, Chapellat H, Keel LH. Robust control: the parametric approach. Upper Saddle River, New Jersey. 1995.

6. Li C, Ye Z, Wang Y, Liu L. Design of attitude decoupling control system for BTT missile using quantitative feedback theory. In: The 2010 International Conference on Modelling, Identification and Control (ICMIC), 17 July 2010; IEEE. pp. 819-824

7. Zhen S, Fei W, \& Xiu-zhi W. Design of missile lateral channel controller based on QFT. In: 2011 International Conference on Computational and Information Sciences, 21 October 2011; IEEE. pp. 917-920.

8. Saxena AR, Veerachary, M. QFT based robust controller design for fourth- order boost dc-dc switching power converter. In: Joint International Conference on Power Electronics, Drives and Energy Systems (PEDES) \& 2010 Power India, 20 December 2010; IEEE. pp. 1-6.

9. Khodabakhshian A, \& Hemmati R. Robust decentralized multimachine power system stabilizer design using quantitative feedback theory. Int. J. Electr. Power Energy Syst. 2012; 41(1): 112-119.

10. Alavi SM, Saif M. A QFT-based decentralised design approach for integrated fault detection and control. IEEE Trans. Control Syst. Technol. 2012; 20(5): 1366-1375.

11. Xu D, He K, Wei Y, Zhao J. Research on QFT controller design for LOS stabilization system of opto-electronic load for UAV. In: $10^{\text {th }}$ World Congress on Intelligent Control and Automation (WCICA), 6 July 2012; IEEE. pp. 1982-1986.

12. Ke L, Zhengzhong W, Qiyou C. Design of flight control system for tiltrotor conversion using QFT. In: $26^{\text {th }}$ Chinese Control And Decision Conference (CCDC), 1 May 2014; IEEE. pp. 3073-3076.

13. Amini F, Katebi J. Application of a robust QFT linear control in civil engineering. In: $14^{\text {th }}$ World Conference on Earthquake Engineering. 2008

14. Gera A, Horowitz I. (1980). Optimization of the loop transfer function. Int. J. Control 1980; 31(2): 389-398.

15. Ballance DJ, Gawthrop PJ. Control systems design via a quantitative feedback theory approach. In: International Conference on Control 1991 (Control'91), 25 March 1991: IET. pp. 476-480.

16. Nandakumar R, Halikias GD, Zolotas A. Robust control design of a hydraulic actuator using the QFT method. In: European Control Conference (ECC), 2 July 2007: IEEE. pp. 2908-2915).

17. Comasolivas R, Escobet T, Quevedo J. Automatic loop shaping of QFT applied to an active control design. In: $19^{\text {th }}$ Mediterranean Conference on Control \& Automation (MED), 20 June 2011: IEEE. pp. 718-723.

18. Yaniv O. Automatic loop shaping of MIMO controllers satisfying sensitivity specifications. J. Dyn. Syst. Meas. Contr. 2006; 128(2): 463- 471.

19. Zolotas AC, Halikias GD. Optimal design of PID controllers using the QFT method. IET Control Theory Appl. 1999; 146(6): 585-589.

20. Patil MD, Nataraj PSV. Automated synthesis of multivariable QFT controller using interval constraint satisfaction technique. J. Process Control 2012; 22(4): 751-765.

21. Kalla R, Nataraj, PSV. Synthesis of fractional-order QFT controllers using interval constraint satisfaction technique. In: $4^{\text {th }}$ IFAC Workshop on Fractional Differentiation and Its Applications (FDA'10), 2010.

22. Patil MD, Nataraj PSV, Vyawahare VA. Automated design of fractional PI QFT controller using interval constraint satisfaction technique (ICST). Nonlinear Dyn. 2012; 69(3): 1405-1422.

23. Jeyasenthil R, Nataraj PSV. Automatic Loop Shaping in QFT Using Hybrid Optimization and Consistency Technique. Dyn. Control of Process Syst. 2013; 10(1): 427-432.
24. Patil MD, Nataraj PSV. Design of Robust QFT Controllers and Prefilters for $3 \times 3$ Distillation Column. In: Annual IEEE India Conference (INDICON), 13 December 2013: IEEE. pp. 1-6.

25. Nataraj PSV, Patil MD. Robust control design for nonlinear magnetic levitation system using quantitative feedback theory (QFT). In: Annual IEEE India Conference, 11 December 2008: IEEE. pp. 365-370.

26. Goldsztejn A, Goualard F, Granvilliers L, Jermann C, Jeyasenthil $\mathrm{R}$, Nataraj PSV, Purohit H. Robust controller and pre-filter design using QFT and interval constraint techniques. In: $7^{\text {th }}$ International Workshop on Constraint Programming and Decision Making, 2014.

27. Garcia-Sanz M, Guillen JC. Automatic loop-shaping of QFT robust controllers via genetic algorithms. In: $3^{\text {rd }}$ IFAC Symposium Robust Control Design 2000 (ROCOND 2000), 2000: Elsevier. pp. 603608.

28. Chen, WH, Ballance DJ, Feng W, Li Y. Genetic algorithm enabled computer-automated design of QFT control systems. In: IEEE International Symposium on Computer Aided Control System Design, 1999., 1999: IEEE. pp. 492-497.

29. Kim MS, Chung CS. Automatic loop-shaping of QFT controllers using GAs and evolutionary computation. In: AI 2005: Advances in Artificial Intelligence, 1 January 2005: Springer Berlin Heidelberg. pp. 1096-1100.

30. Molins C, Garcia-Sanz M. Automatic loop-shaping of QFT robust controllers. In: IEEE National Aerospace \& Electronics Conference (NAECON), 21 July 2009: IEEE. pp. 103-110.

31. Satpati B, Koley C, Datta S. Robust PID controller design using particle swarm optimization-enabled automated quantitative feedback theory approach for a first-order lag system with minimal dead time. Syst. Sci. Control Eng. 2014; 2(1): 502-511.

32. Meng L, Xue D. Automatic loop shaping in fractional-order QFT controllers using particle swarm optimization. In: IEEE International Conference on Control and Automation, 9 December 2009: IEEE. pp. 2182-2187.

33. Meng L, Xue D. Design of a new fractional-order QFT controller based on automatic loop shaping. In: $8^{\text {th }}$ World Congress on Intelligent Control and Automation (WCICA), 7 July 2010: IEEE. pp. 3722-3727.

34. Meng L, Xue D. QFT fractional order robust controller for nonminimum phase hydro power plant. In: IEEE International Conference on Computer Science and Automation Engineering (CSAE), 25 May 2012: IEEE. pp. 94-98.

35. Ali HI, Noor SBBM, Bashi SM, Marhaban MH. Quantitative Feedback Theory control design using particle swarm optimization method. Trans. Inst. Measurement Control 2011: 34; 463-476.

36. French IG, Cox CS. The robust control of a modern electropneumatic actuator. In: International Conference on Control. CONTROL 88, April 1988: IET. pp. 47-52.

37. Peter B. Pneumatic drives system design, modeling and control. Springer, Verlag Berlin Heidelberg, 2007.

38. Horowitz I. Synthesis of Feedback Systems. New York, USA: Academic Press, 1963.

39. Eberhart, Russ C., and James Kennedy. "A new optimizer using particle swarm theory." In Proceedings of the sixth international symposium on micro machine and human science, vol. 1, pp. 3943. 1995 .

40. Coello, Carlos A. Coello, and Maximino Salazar Lechuga. "MOPSO: A proposal for multiple objective particle swarm optimization." In Evolutionary Computation, 2002. CEC'02. Proceedings of the 2002 Congress on, vol. 2, pp. 1051-1056. IEEE, 2002.

41. Durillo, Juan J., José García-Nieto, Antonio J. Nebro, Carlos A. Coello Coello, Francisco Luna, and Enrique Alba. "Multi-objective particle swarm optimizers: An experimental comparison." In Evolutionary Multi-Criterion Optimization, pp. 495-509. Springer Berlin Heidelberg, 2009.

42. Reynoso-Meza G, Blasco X, Sanchis J, Herrero J M. Comparison of design concepts in multi-criteria decision-making using level diagrams. Inf. Sci. 2013; 221: 124-141. 